\title{
Prevalence and Antimicrobial Susceptibility of Bacteria Isolated from Septic Wounds among Patients Attending Uganda Martyrs' Hospital Lubaga.
}

\author{
Richard Musoke ${ }^{a, 1}$, Nathan Lubowa Musisia \\ ${ }^{a}$ College of Veterinary Medicine, Animal Resources and Biosecurity, Makerere University
}

Abstract

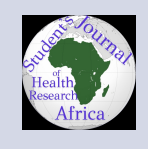

Background: ${ }^{a}$

Wound infections are associated with increased morbidity and mortality. Etiologic agents of wound infections vary with geographical locations. Pathogens that infect wounds can be part of normal flora or acquired from the hospital environment. This study aimed to determine the prevalence of wound infections, investigate the profile of pathogens cultured from an infected wound and determine their antimicrobial resistance pattern to commonly prescribed antibiotics.

Methodology:

A prospective cross-sectional study was conducted at Uganda Martyrs' Hospital Lubaga from March 2020 to May 2020. Swabs from different types of wounds were processed to investigate etiologic agents using the standard microbiological technique. Antimicrobial susceptibility tests were done using a simple disc diffusion technique.

Results:

Out of 210 wound swab samples analyzed, 125(59.5\%) were culture positive. 20(16\%) of the culture had mixed infections and a total of 238 bacteria were isolated from 205 cases. Staphylococcus aureus was the most frequently isolated pathogen which accounted for 94 (75.2\%) of isolates followed by Proteus 11 (8.8\%). The sensitivity rates of Ciprofloxacin, ceftriaxone, and gentamicin were $80.6 \%, 80.6 \%$, and $74.2 \%$ respectively.

Conclusions and recommendation:

S. aureus and Proteus were the predominant causes of wound infections. Ciprofloxacin, ceftriaxone, and Gentamicin were the most effective drugs. Periodic surveillance of the species of bacteria involved in wound infection and determination of their antimicrobial resistance is recommended for empirical treatment.

\footnotetext{
${ }^{a}$ email: musokerichard137@gmail.com

date submitted: 12th/03/2021 date ac-

cepted: 15 th/03/2021
}

\section{Background}

Bacterial infections of wounds are among the leading causes of morbidity and mortality throughout the world and are regarded as one of the most common nosocomial infections (Ohalete et al., 2012). Wound infections have been reported to vary between 3 and $11 \%$ in developed countries and are estimated to be as high as $40 \%$ in developing countries (Truong, 2011). In Uganda, previous studies at Mulago National Referral Hospital showed that $28.7 \%$ of the SSIs are due to S. aureus, and of these $31.5 \%$ are due to MRSA (Ojulong et al., 2010). Wound infections increase with 
the degree of wound contamination, and it is estimated that $50 \%$ of wounds contaminated by bacteria become clinically infected (Mawalla et al., 2011). Drug resistance impinges on the quality of patient care through its associated mortality, morbidity, and significant economic consequences (Moremi et al., 2012). In hospital practice, 30-50\% of antibiotics are prescribed for surgical prophylaxis and $30-90 \%$ of these prophylaxes are inappropriate (Moremi et al., 2012). Inappropriate use of antibiotics increases selection pressure favoring the emergence of pathogenic drug-resistant bacteria which makes the choice of empirical antimicrobial agents more complicated

According to Kassam et al., (2017), extendedspectrum beta-lactamase (ESBL) producing organisms are another type of common bacteria resistant to antibiotics, ESBL producing Gram-negative rods (GNRs) have spread all over the world.

The prevalence of ESBL producing gram-negative rods varies across the world from 50 to $80 \%$ (Shriyan et al., 2010 and Etok et al., 2012). About $33 \%$ of infections by ESBL producers are deadly (Kassam et al., 2017).

In Tanzania, the death rate due to ESBL producing gram-negative rods is as high as $13.9 \%$ (ReAct, 2012). Comparing to Gram-negative, Grampositive bacteria have been reported to be less prevalent causing wound infections (Osariemen et al., 2013). According to Kassam et al., (2017), Staphylococcus aureus has been reported to be the most common isolated bacteria from different wound types. Pseudomonas aeruginosa is commonly isolated in infected wounds following surgeries and burns whereas Enterococcus species (Kassam et al., 2017), and Enterobacteriaceae are commonly isolated from wounds in immune-compromised patients and abdominal surgeries (Muhammed et al., 2013). The majority of the isolates from infected wounds are known to be resistant to ampicillin and amoxicillin (Kassam et al., 2017). Large numbers of $S$. aureus are methicillin-resistant S. aureus (MRSA) and most bacteria isolated are sensitive to quinolones, aminoglycosides, and monobactam (Etok et al., 2012). Infection in a wound delays healing prolongs hospital stay, increases trauma, poses risk for disarticulation and amputation, increases the need for medical care, and increases treatment costs (ReAct, 2012 and Osariemen et al., 2013). This makes infection of wounds a matter of concern and makes it necessary to study the causative agents of these infections and their antibiogram (Kassam et al., 2017). Therefore, this study focused on bacterial isolates and their antimicrobial susceptibility profiles of wound infections among patients in Uganda Martyrs' Hospital Lubaga.

In resource-limited countries with inadequate diagnostic facilities, the spectrum of microorganisms causing wound infections and their antibiotic resistance patterns are only superficially understood (Lia et al., 2018). Pathogen-specific treatment for severe wounds is difficult if the disease-causing agents remain unknown. The widespread and prolonged use of antibiotics leads to the emergence of resistant bacterial pathogens in wound infections contributing to high morbidity and mortality rates (Amare et al., 2011).

Information on bacterial isolates and their antimicrobial susceptibility patterns from the patient at Uganda Martyrs' Hospital Lubaga is limited. Thus, this study aimed to determine the prevalence and antimicrobial susceptibility of bacterial isolates at Uganda Martyrs' Hospital Lubaga in Kampala District.

\section{MATERIALS AND METHODS Study area}

The study was carried out in Lubaga hospital which is a private not-for-profit hospital under the framework of the Uganda Catholic Medical Bureau. It is located on Lubaga Hill about $3 \mathrm{~km}$ from the city center and is bordered by 8 parishes which include; Ndeeba, Kabowa, Nateete, Mutundwe, Lubaga, Busega, and Najjanankumbi I and II. It has a catchment population of 191,107 people (Financial year Report 2019-2020). As of 2015 to date, about 340 new patients have been registered.

It is a fully-fledged hospital rendering both outpatient and inpatient services. It renders surgical, internal medicine, maternity, antenatal and diagnostic services like laboratory and radiology. It has children's wards, medical, surgical, maternity wards, and also three operating theatres.

In October 2012 the Board decided that the name of the hospital should be changed: from previously Rubaga Hospital to Lubaga Hospital. The Board also clarified that the full name of the hospital is now: Uganda Martyrs' Hospital Lubaga.

\section{Study design and duration}


A hospital-based cross-sectional study was conducted from March 2020 to May 2020 at Uganda Martyrs' Hospital Lubaga.

\section{Study population}

The study population included both outpatients and patients admitted at Uganda Martyrs' Hospital Lubaga with wound infections during the study period.

\section{Sample size calculation}

This was calculated using Kish and Leslie formula (1965)

$$
\text { Sample size; } N=Z^{2} p q
$$

Where $\mathrm{N}$ - Required sample size.

Z- Standard deviation at 95\% confidence interval which is 1.96 .

p- Estimated proportion of the target population having the characteristics of interest.

$\mathrm{d}$ - Acceptable error margin which in this case is set at 0.05

$$
\begin{aligned}
& q-(1-p) \\
& N=1.96^{2} \times 0.164 \times 0.836 \\
& \quad 0.0025 \\
& =210
\end{aligned}
$$

Therefore, the sample size was 210 study participants.

\section{Study variables}

The dependent variable was bacterial isolates associated with wound infection and drug resistance pattern whereas the independent variable was age and sex.

\section{Inclusion and exclusion criteria Inclusion criteria}

Patients with wound infection and patients who agreed to participate by giving informed consent

\section{Exclusion criteria}

Patients who did not have wound infection based on clinical examination during the study period were excluded from the study.

\section{Sampling procedure}

Consecutive sampling technique was employed to include study participants who met the inclusion criteria

\section{Data collection}

A predesigned and structured questionnaire was developed and used for the collection of data on socio-demographic characteristics (age and sex) of the patient.

\section{Specimens collection}

Samples (pus swabs) were collected from patients with wound infections by clinicians and they were sent to the laboratory immediately for culture (See appendix I).

\section{Sample processing}

On arrival in the laboratory, the swabs were inoculated onto the prepared culture media which

Consisted of blood agar plates and MacConkey plates. These plates were then incubated at $37^{\circ} \mathrm{C}$ for $24-48$ hours and inspected for bacterial growth.

\section{Biochemical test}

Colonies from primary cultures were extracted and used for carrying out biochemical tests for the final isolation and identification of the organisms. Gram-negative rods were identified by performing a range of tests that included; motility tests, TSI, urease, indole, oxidase, and Simon's citrate agar.

\section{Susceptibility testing}

The drug diffusion disc technique developed by Bauer et al., (1966) was used to assess the susceptibility of the bacterial isolates to the common antibiotics used for treatment at Uganda Martyrs' hospital Lubaga. The test organism was picked using a sterile wire loop, emulsified in sterile broth, and incubated for two hours to let the organisms attain their log growth phase. The density of the suspension was matched with the standard opacity of 0.5 McFarland barium sulphate solution, after which a sterile swab containing the isolate was uniformly seeded onto the Mueller Hinton agar (Oxoid) plate. Antibiotic discs impregnated with different drugs were placed at prescribed regions on the plate and incubated for $18-24$ hours at $37^{\circ} \mathrm{C}$. Zones of inhibition were indicated by the levels of clearing around the antibiotic discs and interpreted using CLSI 2014 guidelines where sensitivity was shown by clearance around the antibiotic disc and resistance indicated by no clearance measured in millimeters.

The Gram-positive isolates obtained were tested against trimethoprim-sulfamethoxazole $25 / 235 \mu \mathrm{g}$ , penicillin (10IU , erythromycin $(15 \mu \mathrm{g}$, vancomycin $(30 \mu \mathrm{g}$, cefoxtin $(30 \mu \mathrm{g}$, and clindamycin $(2 \mu \mathrm{g})$. Gram-negative bacterial isolates were tested with ciprofloxacin $(5 \mu \mathrm{g})$, gentamicin $(10 \mu$ g), trimethoprim-sulfamethoxazole $(1.25 / 23.5 \mu \mathrm{g})$, chloramphenicol $(30 \mu \mathrm{g})$, nalidixic acid $(15 \mu \mathrm{g})$ and ceftriaxone $(30 \mu \mathrm{g})$.

\section{Quality control}

The authenticity and quality of the results to be obtained were dependent on the integrity of the 
procedures and protocols that were involved from the time of collection to the analysis of the samples collected. As such, SOPs as per CLSI 2014 were strongly adhered to during the pre-analytical, analytical, and post-analytical processing of the samples.

Also, all the materials and reagents used in the study were adequately controlled to ensure sterility throughout the entire process. In addition to that, all prepared culture media batches were tested for sterility and performance.

As stated by Bauer et al., (1966), standard inoculums of bacterial suspension for susceptibility testing were prepared using reference from 0.5 McFarland barium sulphate solution.

Internationally recognized control strains including Staphylococcus aureus (ATCC 25923),

Escherichia coli (ATCC 25922) and Pseudomonas aeruginosa (ATCC 27853) were incorporated into the study.

\section{Ethical considerations}

The research proposal together with an introductory letter from COVAB was submitted to the Lubaga Hospital research committee and ethical approval was obtained. Ethical issues conformed to international regulations of research, written consent was obtained from every study participant and the results from laboratory analysis were communicated to the responsible physician who then passed them on to study participants for treatment. The information from the patients was treated with confidentiality and because of this, study numbers and not names were used during data collection and presentation.

\section{Dissemination of results}

Copies of the dissertation will be made and disseminated to Makerere University, to the management of Lubaga Hospital and the final copy will be retained by the researcher

\section{RESULTS}

\section{Demography}

A total of 210 patients with wound infection were included in this study, out of which, 172(81.9\%) were male and $38(18.1 \%)$ were female. resulting in an overall male-to-female ratio of 1:4.5. The age of the patients ranged from 1 year to 68 years, with a mean age of $35(S D=11.6)$ years. The infection rate was relatively high $(41 \%)$ in the age group of 21-30 years old followed by the 31-40 years of age group (20\%). Most of the respondents with wound infections were students (52.8\%) followed by businessmen/ladies (24\%). The demographic characteristics of respondents involved in this study are presented in Table (Table1)

\subsection{Prevalence of wound infection}

Out of a total of 210 swab samples collected and tested, 125 (59.5\%) of them presented with bacterial growth whereas the remaining 85 (40.5\%) of the swabs had no growth after 48 hours of incubation. So, this gave a prevalence of $59.5 \%$.

\subsection{Common bacteria associated with wound infections Gram stain reaction of the organisms cultured}

From a total of 125 samples that showed bacterial growth, only 31 (24.8\%) were Gram negative while the rest 94 (75.2\%) were Gram positive (Table 2).

Staphylococcus aureus was the most predominant isolate with $94(75.2 \%)$ followed by Proteus spp with $11(8.8 \%)$, E. coli, K. pneumonia, P. aeruginosa and Enterobacter presenting 9(7.2\%), 5(4\%), 4(3.2\%) and 2(1.6\%) respectively.

All mixed infections in this study involved Grampositive and Gram-negative bacteria with S. aureus and $E$. coli show the most common association in $9(45 \%)$ cases. Infections with S. aureus and Proteus spp, 7(35\%) S. aureus and Pseudomonas aeroginesa 4(20\%) were among the mixed infections, there was no case with more than two organisms in our study.

Antimicrobial susceptibility of the bacterial isolates from the septic wound among patients seeking medical care at Uganda Martyrs' Hospital Lubaga

\section{Gram-positive antimicrobial susceptibility pattern}

Staphylococcus aureus was the only Gram-positive bacteria isolated. Their susceptibility patterns were determined against a profile set of 12 antibiotics. Vancomycin and teicoplanin showed sensitivity in all $125(100 \%)$ of the Gram-positive isolates followed by clindamycin with 104(83.2\%) sensitivity and $21(16.8 \%)$ resistance, gentamycin with $102(81.9 \%)$ sensitivity, and $23(18.1 \%)$ resistance while the least effective antibiotic was tetracycline with $37(30 \%)$ sensitivity and $88(70 \%)$ resistance, penicillin G with 32 (25.1\%) sensitivity and 93(74.9\%) 
Table 1. Demographic characteristics of study respondents with wound infections at Uganda Martyrs' Hospital Lubagas.

\begin{tabular}{lll}
\hline Age group (years) & No. of Culture positive $(\mathrm{N}=125)$ & No. of culture negative $(\mathrm{N}=85)$ \\
$<10$ & $12(10)$ & $12(14)$ \\
$11-20$ & $10(8)$ & $16(19.2)$ \\
$21-30$ & $51(41)$ & $26(30.6)$ \\
$31-40$ & $25(20)$ & $18(21)$ \\
$41-50$ & $18(14)$ & $11(12.8)$ \\
$<51$ & $9(7)$ & $2(2.4)$ \\
Education level & & \\
Preschool & $7(5.6)$ & $4(4.7)$ \\
Primary restore & $11(8.8)$ & $15(17.6)$ \\
Secondary & $55(44)$ & $9(10.6)$ \\
Tertiary & $52(41.6)$ & $57(67.1)$ \\
Occupation & & \\
Preschool & $7(5.6)$ & $4(5)$ \\
Students & $66(52.8)$ & $24(28)$ \\
Peasant & $22(17.6)$ & $19(22.3)$ \\
Business men/ Lady & $30(24)$ & $38(44.7)$ \\
\hline
\end{tabular}

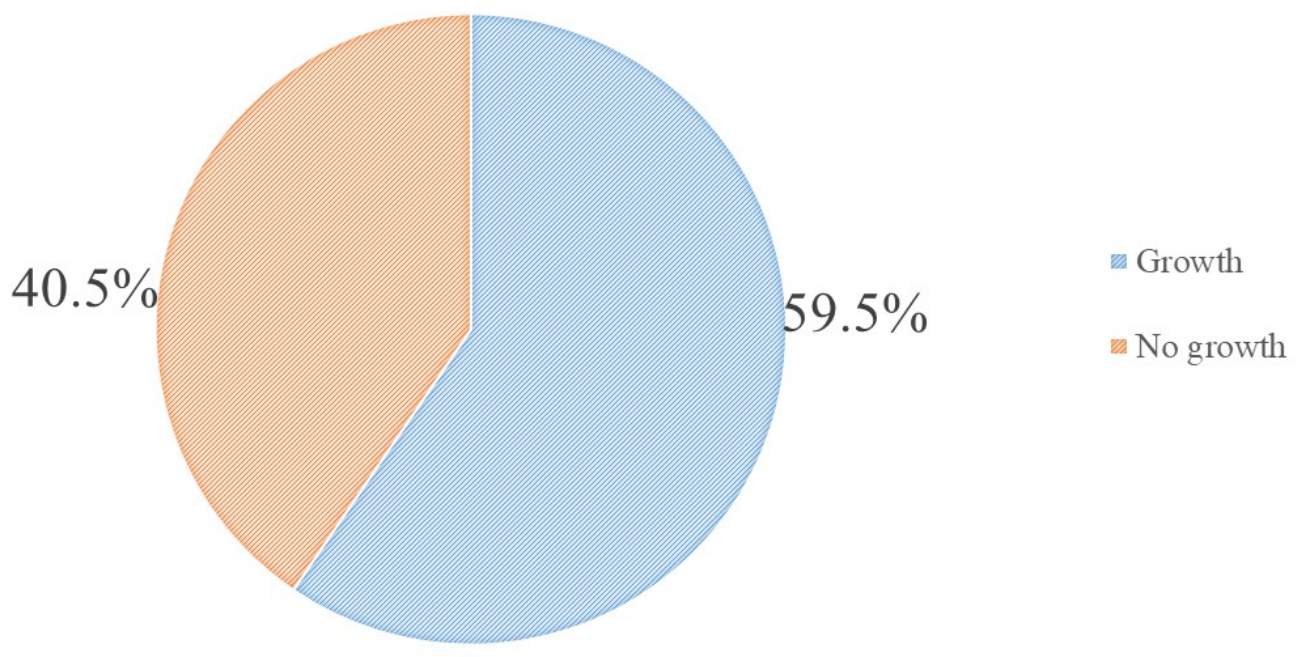

Chart 1. Prevalence of wound infections caused by bacteria among patients seeking medical care at Uganda Martyrs' Hospital Lubaga

Table 2. Gram stain reaction of the isolates obtained wound infection in respondents at Uganda Martyrs' Hospital Lubaga

\begin{tabular}{lll}
\hline Gram stain reaction & Frequency & Percentage \\
Positive & 94 & 75.2 \\
Negative & 31 & 24.8 \\
Total & 125 & 100.0 \\
\hline
\end{tabular}




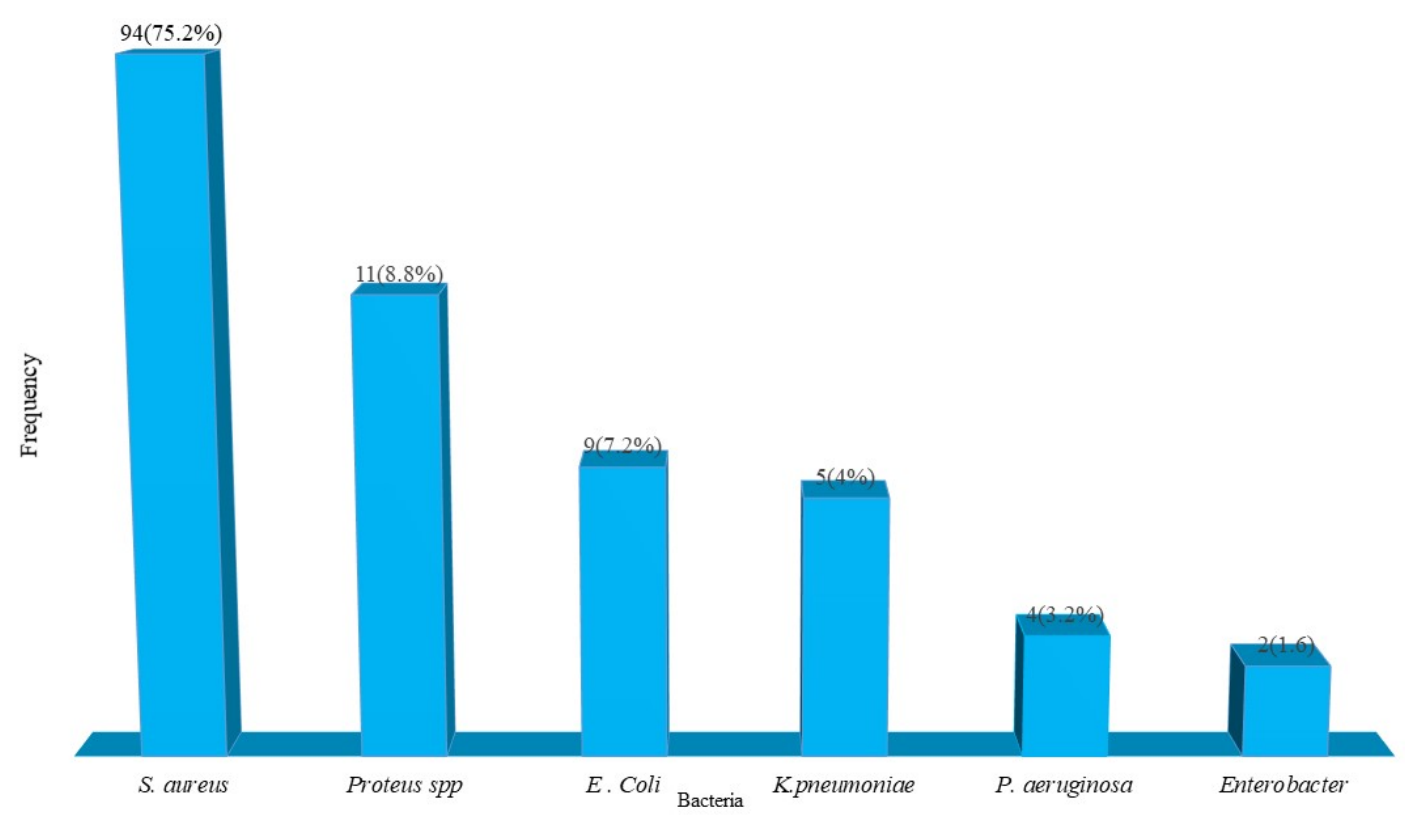

Chart 2. Frequency of the bacteria isolated from the swabs with bacterial growth in respondents seeking medical care at Uganda Martyrs' Hospital Lubaga

Table 3. Type and frequency of pathogens with mixed infection from wound infections in respondents seeking medical care at Uganda Martyrs' Hospital Lubaga

\begin{tabular}{lll}
\hline Pathogen & Frequency & Percentage (\%) \\
S. aureus and E. coli & 9 & 45 \\
S. aureus and Proteus & 7 & 35 \\
S. aureus and P. aeruginosa & 4 & 20 \\
Total & 20 & 100 \\
\hline
\end{tabular}

resistance, ampicillin with $31(25 \%)$ sensitivity and $94(75 \%)$ resistance cotrimoxazol with $13(10 \%)$ sensitivity and $112(90 \%)$ resistance. However, S. aureus showed $100 \%$ resistance to ciprofloxacin, cefotaxime, and oxacillin each. Vancomycin together with teicoplanin were the most effective antibiotics from the results.

\subsection{Gram negative antimicrobial susceptibility pattern}

Proteus vulgaris 11(8.8\%), E. coli 9(7.2\%), Klebsiella pneumoniae 5(4\%) Pseudomonas aeroginesa 4(3.2\%), and Enterobacter species 2(1.6\%) were the gramnegative isolates obtained in the study, representing a total of 31 isolates. The drug susceptibility patterns for the isolates were tested against a panel of 6 antibiotics and the results revealed that ciprofloxacin and ceftriaxone had the highest sen- sitivity of 25(80.6\%). Gentamycin had sensitivity of 23(74.2\%), Ampicillin with 21(67.7\%), nalidixic with 19(61\%) while chloramphenicol had the highest resistance of $21(67.7 \%)$. This information showed that ceftriaxone, ciprofloxacin and gentamycin are the best drugs of choice for treating infections caused by Gram negative bacteria.

\section{DISCUSSION}

A prevalence of $59.5 \%$ of wound infections was observed in this study. This was higher than that previously reported in Mbarara Uganda with a prevalence of 16.4\% (Lubega et al., 2017), Nepal with a prevalence of 23\% (Giri et al., 2013), Tanzania 26\% (Mawalla et al., 2011) and Ethiopia 10.6\% (Mulu et al., 2012). However, the prevalence observed in this study is lower than that previously observed in North East Ethiopia 70.5\% (Mulugeta et al., 2011), 


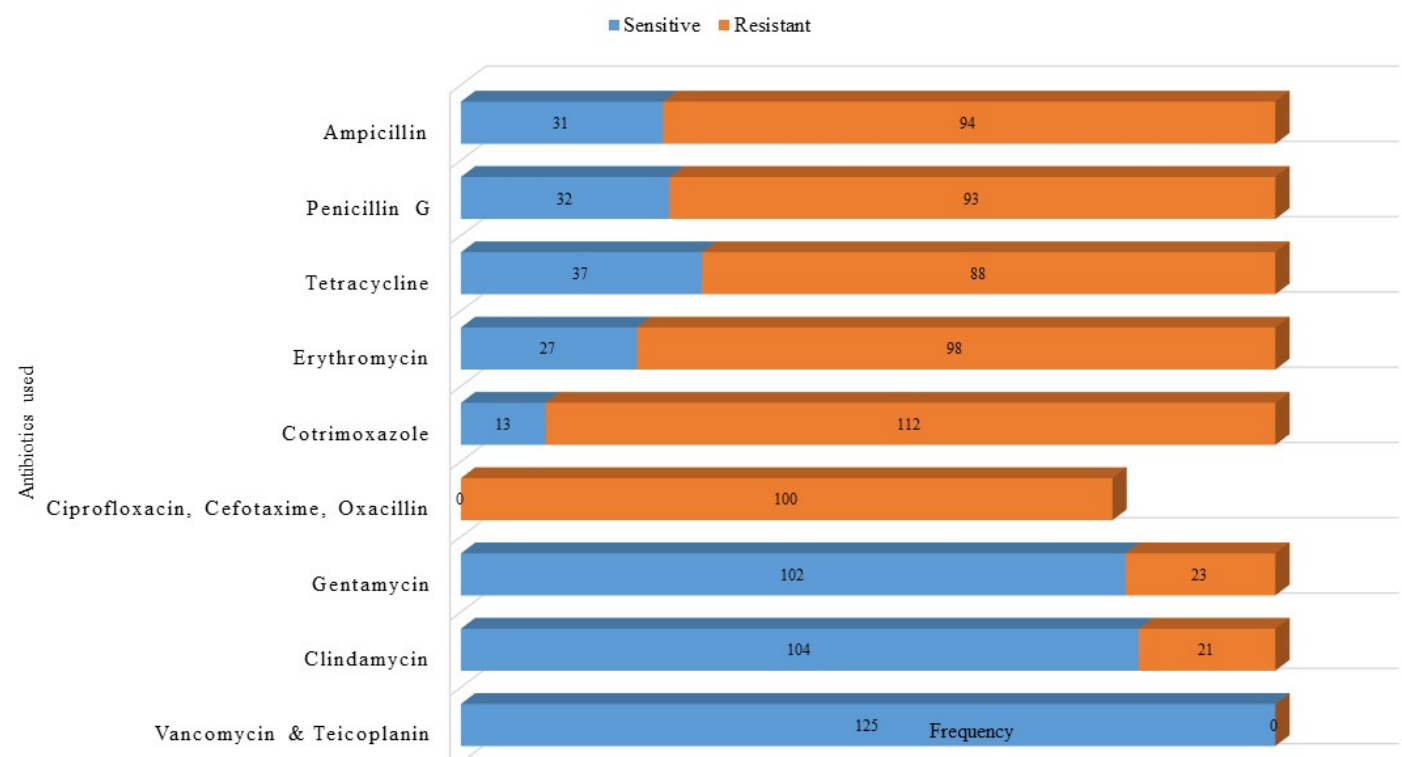

Chart 3. Gram positive antimicrobial susceptibility pattern in respondents seeking medical care at Uganda Martyrs' Hospital Lubaga

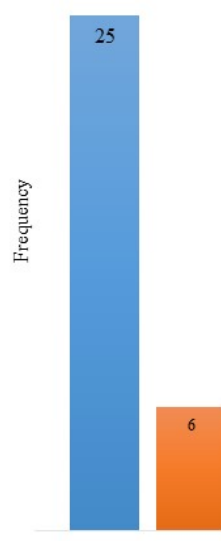

Ciprofloxacin

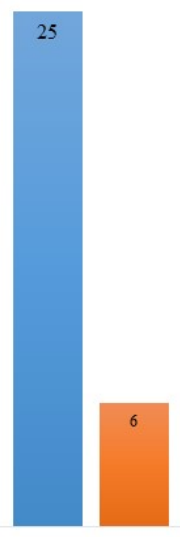

Ceftriax one

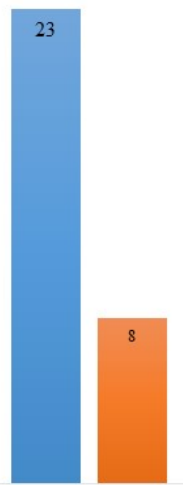

Gentamycin

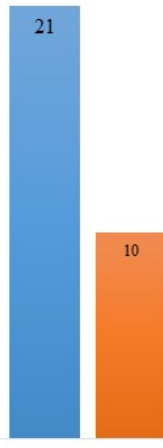

Ampicillin

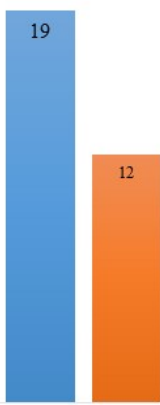

Nalidixic acid

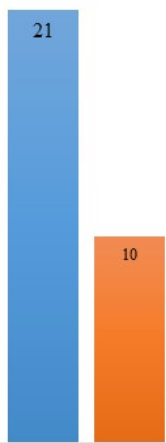

Chloramphenicol

= sensitive $\quad$ resistance

Chart 4. Gram negative isolate antimicrobial susceptibility pattern in respondents seeking medical care at Uganda Martyrs' Hospital Lubaga 
Addisa Ababa Ethiopia 83.3\% (Tigist et al., 2012). The higher prevalence of wound infection in this study could be attributed to poor sterility during surgical procedures, poor hygiene due to poor standards of living in communities, and lack of reliable surveillance methods for discharged patients.

The Gram-positive bacteria isolated from the pus swab collected from wound infections was Staphylococcus aureus $94(75.2 \%)$ as the most prevalent bacterial agent isolated in this study. This observation agreed with several previous studies conducted at different places (Mulugeta et al., 2011; Tigist et al., 2012). However, Girma et al., (2013) reported Proteus species as the most prevalent agent for wound infections. This deviation might be due to variation in the distribution of microbial agents between different geographical locations and regions within the same country. The possible reason for the high frequency of Staphylococcus aureus is that these bacteria are commonly found in the hospital environment (Girma et al., 2013) which might increase wound infection rate and crosscontamination among admitted patients. Also, these bacteria are normal flora in a healthy person (especially S. aureus on the skin) when they get the skin damaged and soft tissue they can easily spread as explained by Khana et al., (2010).

The prevalence of mixed infections 20(16\%) observed in this study was slightly lower than that reported in Jimma University Specialize Hospital Ethiopia 22.9\% (Girma et al., 2013) and Nigeria 33.2\% (Agbe et al., 2011) reported in previous studies.

Amongst the Gram-negatives, Proteus vulgaris $8.8 \%(11 / 31)$ was the most prevalent isolate. Others including, E. coli 9(7.2\%), Klebsiella pneumonia 5(4\%), Pseudomonas aeroginesa 4(3.2\%), and Enterobacter 2(1.6\%) were amongst the isolates obtained. The findings are in agreement with a similar study done by Ekrami et al., (2014) in which proteus was the most predominant Gram-negative isolate identified.

According to the study, the most effective antibiotic for Gram-positive isolates was vancomycin with $100 \%$ sensitivity, followed by clindamycin and trimethoprim-sulfamethoxazole with $83 \%$ and $61 \%$ sensitivities respectively. However, an increased resistance was observed to penicillin, cefoxtin, and erythromycin with $93 \%, 48 \%$, and $48 \%$ resistance respectively. Similar studies revealed $100 \%$ resistance rates for penicillin G, and clindamycin (Abdal- lah et al., 2015) and 100\% resistance to penicillin $G$ (Kajela, 2013). These trends could be as a result of the increasing poor use and abuse of antibiotics by the general population resulting in a rise in the number of resistant bacterial strains and their relatively high availability as they are cheap to obtain.

The study deduced the most effective antibiotic for Gram-negative isolates was ciprofloxacin,

ceftriaxone, and gentamycin with 80.6\%, 80.6\%, and $74.2 \%$ sensitivity respectively. However, the least effective antibiotic was chloramphenicol with $67.7 \%$ resistances. Other similar studies reported low susceptibilities to erythromycin at $7.1 \%$ and chloramphenicol at 6.5\% (Kihla et al., 2014). The high resistance is reflective of the ready availability of these drugs in the population and the increasing abuse of prescriptions.

\section{CONCLUSIONS AND RECOMMENDATION}

\section{Conclusion}

The overall general prevalence of the isolated microbes was high with $59.5 \%$. The results from the study also showed that Staphylococcus aureus was the most predominant bacteria found contaminating wound infections. Other bacterial isolates included Klebsiella pneumoniae, Proteus vulgaris, E. coli, pseudomonas spp, and Enterobacter spp.

\section{Recommendations}

A high prevalence of potential nosocomial infection-causing pathogens observed implies insufficient sterilization and decontamination protocols and therefore, we recommend reconsiderations about the type, strength, usage, and quantity of disinfectant used by the

\section{Hospital administration.}

From the study, increasing resistance trends of bacteria against single or multiple antibiotics were observed. This is possibly due to the abuse of antibiotics described and poor decontamination and sterilization protocols.

Several organisms were resistant to multiple antibiotics from the drug susceptibility patterns from the study. We, therefore, recommend the use of vancomycin for Gram positives, ciprofloxacin, and ceftriaxone for Gram-negatives which can come in handy most especially in the empiric treatment as bacterial culture results tend to take a while before returning to the ward. 
Additionally, routine infection control surveillance and monitoring systems should be put in the hospital and the whole country at large to identify emerging pathogens and their respective susceptibility patterns to antibiotics.

Vancomycin is the most recommended antibiotic of choice for the treatment of Staphylococcal infections followed by clindamycin. Ciprofloxacin was the recommended drug of choice for the treatment of gram-negative infections.

\section{Acknowledgement}

I would like to extend my sincere gratitude to God for enabling me complete my research successfully.

I also thank my supervisor for the advice and guidance he has given to me in this research writing. I also thank him for sacrificing his free time especially on public holidays in order to help me finish the research on time.

In a special way, I thank the Laboratory Manager and the microbiology in-charge of UgandaMartyrs' Hospital Lubaga Laboratory, for their support and encouragement during data collection.

Finally, I thank all my classmates, Lecturers and the staff of Uganda Martyrs' Hospital Laboratory, Lubaga for having provided a good study environment and support throughout the entire course. It has been great learning and sharing with you all, I will always remember your help and the encouraging words given to me in the course of this study. May the good Lord bless you and reward you abundantly.

\section{LIST OF ABBREVIATIONS AND ACRONYMS}

$\begin{array}{ll}\text { AHS } & \text { Allied Health Sciences } \\ \text { API } & \text { Analytical profile index } \\ \text { CDC } & \text { Centre for Disease Control and prevention } \\ \text { CLSI } & \text { Clinical and Laboratory Standards Insti- } \\ \text { tute } & \\ \text { CoNS } & \text { Coagulase Negative Staphylococcus } \\ \text { species } & \\ \text { ESBL } & \text { Extended spectrum beta-lactamase } \\ \text { GNRS } & \text { Gram-negative rods IHSU Interna- } \\ \text { tional Health Sciences University } & \\ \text { MDR } & \text { Multidrug resistance } \\ \text { MRSA } & \text { Methicillin Resistant S. aureus } \\ \text { REC } & \text { Research Ethics Committee }\end{array}$

\author{
SSI Surgical site infections \\ VRE Vancomycin-Resistant Enterococus \\ WHO - World Health Organization
}

\section{Definition of Terms}

Septic wounds: These are also known as infected wounds. Wound care centers define infected wounds as in which bacteria and other microorganisms have colonized, causing a delay in wound healing or deterioration of the wound.

Multidrug resistance: This is an isolate that is non-susceptible to one or more agents in three antimicrobial classes.

Nosocomial infections: Are defined as hospitalacquired infections developing at least $48-72$ hours after hospital admission.

Surgical site infections: These are infections that occur within 30 days after the operation and these infections involve the skin and subcutaneous tissue of the incision. The infection may be indicated by the presence of pus or abscess, fever with the tenderness of the wound, or separation of the edges of the incision exposing the deeper tissues (CDC).

\section{A References}

1) Abdallah, E. M., Ahamed, F., \& Al-Omari, A. S. (2015). "Antibiotic susceptibility patterns of some clinical isolates from Al-Rass General Hospital". International Journal of Biosciences (IJB), 6(9),47-54. https://doi.org/10.12692/ijb/6.9.47-54

2) Amare B, Abdurrahman Z, Moges B, and Ali J, (2011): "Postoperative surgical site bacterial infections and drug susceptibility patterns at Gondar University Teaching Hospital, Northwest Ethiopia," Journal of Bacteriology \& Parasitology, vol. 2, no. 8. https://doi.org/10.4172/2155-9597.1000126

3) Ekrami AR, Kayedani A, Jahangir M, Kalantar E, Jalali M. (2011), "Isolation of common aerobic bacterial pathogens from the environment of seven hospitals", Ahvaz, Iran. J Microbiol, 4(2): 75-82.

4) Etok CA, Edem EN, Ochang E. 2012; Aetiology and antimicrobial studies of surgical wound infections in University of Uyo Teaching Hospital (UUTH) Uyo, Akwa Ibom State, Nigeria. Niger Open Access Scientific Reports.1:1-5.

5) Giri S., Kandel B. P., Pant S., Lakhey P. J., Singh Y. P., Vaidya P. (2013): Risk factors for surgical site infections in abdominal surgery: a study in nepal. 
Surgical Infections. 14(3):313-318. https://doi.org/1 $0.1089 /$ sur.2012.108

6) Girma Godebo, Gebre Kibru and Himanot Tassew. (2013): Multidrug-resistant bacteria isolates in infected wounds at Jimma University Specialized Hospital, Ethiopia. Annals of Clinical Microbiology and Antimicrobials.2013;12(17):1-7. https:// doi.org/10.1186/1476-0711-12-17

7) Kassam, N.A., Damian, D.J., Kajeguka, D. (2017). Spectrum and antibiogram of bacteria isolated from patients presenting with infected wounds in a Tertiary Hospital, northern Tanzania. BMC Res Notes 10, 757. https://doi.org/10.1186/s13104-0173092-9

8) Khanal LK, Jha BK (2010): Prevalence of Methicillin resistant Staphylococcus aureus (MRSA) among skin infection cases at a hospital in Chitwan, Nepal. Nepal Med Coll J 2010; 12:224-228.

9) Kihla, A. J.-F. T., Ngunde, P. J., Mbianda, S. E., Nkwelang, G., \& Ndip, R. N. (2014). Risk factors for wound infection in health care facilities in Buea, Cameroon: aerobic bacterial pathogens and antibiogram of isolates. Pan African Medical Journal, 18(1). https://doi.org/10.11604/pamj.2014.18.6.23 04

10) Lai PS, Bebell LM, Meney C, Valeri L, White MC. (2018): Epidemiology of antibiotic-resistant wound infections from six countries in Africa. Bacteriology Medical Journal of Global Health 2 (Suppl 4): e000475. pmid:29588863. https://doi.org/10.1136 /bmjgh-2017-000475

11) Lubega, A., Joel, B., \& Justina Lucy, N. (2017). Incidence and Etiology of Surgical Site Infections among Emergency Postoperative Patients in Mbarara Regional Referral Hospital, South Western Uganda. Surgery research and practice, 2017. http s://doi.org/10.1155/2017/6365172

12) Lubega, Bazira \& Najjuka, (2017): Incidence and Etiology of Surgical Site Infections among Emergency Postoperative Patients in Mbarara Regional Referral Hospital, South Western Uganda journal of Surgery Research Practtice. Published online on 2017Jan12. https://doi.org/10.1155/2017/636517 2

13) Mawalla. B, Mshana SE, Chalya PL, Imirzalioglu C, Mahalu W. (2011); Predictors of surgical site infections among patients undergoing major surgery at Bugando Medical Centre in Northwestern Tanzania. BMC Surgery 11: 21. https://doi.org/ 10.1186/1471-2482-11-21
14) Mohammad S R, Anil C., \& Abirodh R., (2013). Antimicrobial Susceptibility Patterns of the Bacterial Isolates in Post-Operative Wound Infections in a Tertiary Care Hospital, Kathmandu, Nepal. Open Journal of Medical Microbiology;3:159-163. https:// doi.org/10.4236/ojmm.2013.33024

15) Mohammed A, Adeshina G, Ibrahim YK, (2013); Incidence and antibiotic susceptibility pattern of bacterial isolates from wound infections in a tertiary hospital in Nigeria. Tropical Journal of Pharmaceutical Research. 12(4):617-21. https://doi. org/10.4314/tjpr.v12i4.26

16) Moremi N, Mshana SE, Kamugisha E, Kataraihya J, Tappe D. (2012); Predominance of methicillin resistant Staphylococcus aureus -ST88 and new ST1797 causing wound infection and abscesses. Journal of Infection in Developing Countries 6: 620625. https://doi.org/10.3855/jidc.2093

17) Mulu A, Moges F, Tessema B, Kassu A (2012): Pattern and multiple drug resistance of bacterial pathogens isolated from wound infection at University of Gondar Teaching Hospital. Ethiopian Medical Journal. 44:125-131.

18) Mulu W., Kibru G., Beyene G., Damtie M. (2012): Postoperative nosocomial infections and antimicrobial resistance pattern of bacteria isolates among patients admitted at felege hiwot referral hospital, Bahirdar, Ethiopia. Ethiopian Journal of Health Sciences. 22(1):7-18.

19) Mulugeta K. Azene and Bayeh A. Beyene. (2011) Bacteriology and antibiogram of pathogens from wound infections at Dessie Laboratory, North East Ethiopia. Tanzania Journal of Health Research;13(4):1-10. https://doi.org/10.4314/thrb. v13i4.64901

20) Ohalete C.N, Obi R.K, and EmeaKoroha M. C, (2012): "Bacteriology of different wound infection and their antimicrobial susceptibility patterns in Imo state Nigeria," World Journal of Pharmaceutical Sciences, vol. 13, no. 3, pp. 1155-1172.

21) Ojulong J., Mwambu TP., Joloba M., Bwanga F., \& Kaddu-Mulindwa DH. (2010); Relative prevalence of methicillin resistant Staphylococcus aureus and its susceptibility pattern in Mulago Hospital, Kampala, Uganda. Tanzanian Journal of Health Research 11: 149-153 https://doi.org/10.4314/thrb.v1 $1 \mathrm{i} 3.47703$

22) Osariemen IJ., Olowu SS., Adevbo E., Omon EE., Victoria O., Imuetinyan EJ., (2013); Aerobic bacteria associated with diabetic wounds in patients 
attending clinic in a rural community in Nigeria. Global Res Journal of Microbiology. 3:8-12.

23) ReAct 2012; A fact sheet from ReAct-action on antibiotic resistance. Uppsala;

24) Shriyan A, Sheetal R, Nayak N. (2010); Arobic micro-organism in post-oprative wound infection and their antimicrobial susceptibility patterns. Journal of Clinical Diagnostic Research. 3:2208-16.

25) Tigist A., Gizachew Y., Ayelegn D., Zufan S. (2012). Staphylococcus aures burn Wound infection among patients attending yekatit 12 nts hospital burn unit, Addis Ababa, Ethiopia. Ethiop J Health Sci; 22(3): 209-213.

26) Truong H, Shah SS, Ludmir J, Twananana EO, \& Bafana M, (2011); Staphylococcus aureus skin and soft tissue infections at a tertiary hospital in Botswana. South African Medical Journal 101: 413416. Tanzania. BMC Surgery 11: 21. 